\title{
Developmental stability in hybrids of European bison Bison bonasus and domestic cattle
}

\author{
Alexander S. BARANOV and Vladimir M. ZAKHAROV
}

\begin{abstract}
Baranov A. S. and Zakharov V. M. 1997. Developmental stability in hybrids of European bison Bison bonasus and domestic cattle. [In: Developmental homeostasis in natural populations of mammals: phenetic approach. V. M. Zakharov and A. V. Yablokov, eds]. Acta Theriologica, Suppl. 4: 87-90.

We examined fluctuating asymmetry of 25 characters of skull morphology (foramina, apertures through the bone for nerves and small blood vessels) to estimate the developmental stability of European bison Bison bonasus (Linnaeus, 1758) $(n=34)$, cattle $(n=13)$ and their hybrids (54 hybrids of different generations). Mean number of asymmetrical characters per individual was used as a measure of fluctuating asymmetry. European bison were characterized by a lower developmental stability, compared with cattle. The developmental stability of hybrids was similar to that of cattle and higher than that of European bison. These findings suggest that the genomes of parental forms are similar and that there is no indication of the disruption of genetic coadaptation in their hybrids.
\end{abstract}

N. K. Koltzov Institute of Developmental Biology, Russian Academy of Sciences, Vavilov Str. 26, 117808 Moscow, Russia

Key words: hybrids of European bison and domestic cattle, fluctuating asymmetry, developmental stability, genetic coadaptation

\section{Introduction}

Hybrids between European bison Bison bonasus (Linnaeus, 1758) and domestic cattle are of both fundamental and applied interest. Such crosses produce viable F1 hybrids, but male hybrids appear to be sterile. Male sterility does not improve even after backcrossing with cattle for three generations (Krasińska 1969, 1971a, b, 1979). Nevertheless, all F1 hybrids are viable and show some heterosis. Is male sterility of F1 hybrids caused by small changes in the genome, or is it the result of disturbance of general genetic coadaptation? Developmental stability, which is estimated by fluctuating asymmetry of morphological characters, is a sensitive indicator of an organism's condition. It has been suggested as a measure of genetic coadaptation (Dobzhansky 1950, Reeve 1960, Ferguson 1986, Zakharov 1981, 1987, 1992, Clarke and McKenzie 1992, Graham 1992).

The aim of this study was to estimate the developmental stability of hybrids between European bison and cattle and to compare it with the developmental stability of the parental forms. 


\section{Material and methods}

We used skull collections of European bison, cattle and their hybrids from the Mammal Research Institute of the Polish Academy of Sciences in Białowieża and the Department of Animal Anatomy, Warsaw Agricultural University. Thirty-four skulls from a free-ranging population of European bison in Białowieża Forest and 13 skulls of the "black and white" cattle breed were used to characterize the parental forms. Hybrids were represented by a small sample of $\mathrm{F} 1$ hybrids $(n=7)$ between European bison and cattle and three backcross generations of F1 females backcrossed to cattle (Krasińska 1971a, b, 1979) ( $n=25$ for B1, $n=17$ for B2, $n=5$ for B3).

We examined fluctuating asymmetry of 25 skull characters comprising a number of foramina (as presented in Fig. 1 in Baranov et al. 1997) to estimate developmental stability. The similarity of the skulls of the European bison and cattle allowed us to use the same set of morphological characters for both species. Because there were no indications of directional asymmetry or antisymmetry (Van Valen 1962, Palmer and Strobeck 1986, Zakharov 1987) for the characters, the difference between left and right sides of the skull in a number of foramina ( $(-r)$ was considered fluctuating asymmetry. Different number of foramina on the left and right sides of the skull was regarded as an asymmetrical state of a character. We used the mean number of asymmetrical characters as an index of developmental stability. The pooled samples were compared, as we had not revealed significant sex differences (eg for the bison sample: $t=1.41 \mathrm{df}=32, p>0.05$ ). One-way ANOVA has not revealed significant difference among groups of hybrids studied: F1, B1, B2 and B3 $(F=1.22, \mathrm{df}=3,50$, $p>0.05$ ). Hence, the pooled sample of 54 hybrids was compared with the samples of parental populations. $t$-tests were performed to test differences in the mean number of asymmetrical characters between the three samples under study: hybrids, bisons and cattle (Sokal and Rohlf 1981).

\section{Results}

Comparison of the samples from two parental populations (Table 1) revealed significantly higher fluctuating asymmetry for the European bison than for the cattle $(t=2.97, \mathrm{df}=45, p<0.01)$. The level of fluctuating asymmetry proved to be significantly lower $(t=4.2$, $\mathrm{df}=86, p<0.001)$ in hybrids than in the European bison population and was very similar to that in the cattle. This indicated the same or even higher developmental stability of the hybrids as compared with the parental forms, and European bison in particular.
Table 1. Integrated measure of developmental stability (mean number of asymmetrical characters, NA, for 25 characters of skull morphology, see Fig. 1 in Baranov et al. 1997) in Białowieża population of European bison Bison bonasus, cattle and their hybrids (F1 and backcrosses: B1-B3).

\begin{tabular}{lcr}
\hline Samples & $n$ & $\mathrm{NA} \pm \mathrm{SE}$ \\
\hline Bison & 34 & $10.62 \pm 0.43$ \\
F1 & 7 & $9.29 \pm 1.41$ \\
B1 & 25 & $8.48 \pm 0.46$ \\
B2 & 17 & $7.47 \pm 0.51$ \\
B3 & 5 & $9.00 \pm 0.95$ \\
All hybrids & 54 & $8.31 \pm 0.34$ \\
Cattle & 13 & $8.54 \pm 0.55$ \\
\hline
\end{tabular}

\section{Discussion}

F1 hybrids between European bison and cattle, and three backcross generations (B1, B2, B3) with cattle (Table 1), did not reveal any significant differences in 
developmental stability, as measured by mean number of asymmetrical characters. These results correspond to the fact that even after three generations of backcrossing hybrid females with cattle, hybrid males were still sterile (Krasińska 1971a, b, 1979).

Three possible scenarios can be expected for hybridization of different forms: (1) Hybridization of genetically related forms that have high developmental stability will not affect the developmental stability in resulting progeny, because genetic coadaptation is not disrupted. (2) Hybridization of closely related forms that have low developmental stability - caused by high homozygosity - will lead to an increase of developmental stability in the offspring, resulting from increased heterozygosity and removing of inbreeding depression. (3) Hybridization of genetically divergent forms will result in a decrease in developmental stability because of disruption of genetic coadaptation.

Parental forms in this study had different levels of developmental stability. Higher asymmetry in European bison in Białowieża suggests a decreased developmental stability level, which could be caused by high homozygosity (Olech 1987, 1989). We would expect a decrease in developmental stability in hybrids of European bison and cattle, in light of the knowledge that the hybrid males are sterile. But absence of developmental instability, which would indicate disruption of genetic coadaptation, suggests that the genomes of the parental species are similar. Sterility of hybrid males could be caused by local genetic changes unrelated to the essential genetic differences between the original forms. Similar levels of developmental stability for the parental forms of sibling species of Drosophila and their sterile hybrids, indicating overall similarity of the original forms, have been shown earlier (Wallace 1953, Gupta 1978, Markow and Ricker 1991).

An increase of developmental stability in hybrids, as compared with the Białowieża population of European bison, relates to the earlier obtained data that the decrease in developmental stability of the Białowieża population is a result of increased homozygosity (Baranov et al. 1997). Removing the inbreeding depression could have a stronger positive influence on an organism's condition than the possible adverse effect of some decline in overall genetic coadaptation. Similar result has been obtained in the study of the Mus musculus hybrid zone (Alibert et al. 1994). More data are needed for a final conclusion, but even these preliminary results show the potential usefulness of developmental stability studies to assess the consequences of hybridization between various forms.

Acknowledgements: The work was conducted within the framework of a bilateral agreement between the Russian and Polish Academies of Sciences. We are grateful to Prof Z. Pucek and Dr M. Krasińska for an opportunity to use the skull collection of the Mammal Research Institute PAS, Białowieża (MRI) and Prof F. Kobryńczuk and Dr M. Makowiecka for an opportunity to use the skull collection of the Department of Animal Anatomy, Warsaw Agricultural University and Mr S. Buszko for assistance in using the MRI collection. Scientific staff of the MRI is acknowledged for the stimulating discussion of the results. We are very grateful to anonymous referees who provided very helpful comments and corrections of English. 


\section{References}

Alibert P., Renaud S., Dod B., Bonhomme F. and Auffray J-C. 1994. Fluctuating asymmery in the Mus musculus hybrid zone: a heterotic effect in disrupted co-adapted genomes. Proceedings of the Royal Society of London 258: 53-59.

Baranov A. S., Pucek Z., Kiseleva E. G. and Zakharov V. M. 1997. Developmental stability of skull morphology in European bison Bison bonasus. [In: Developmental homeostasis in natural populations of mammals: phenetic approach. V. M. Zakharov and A. V. Yablokov, dds]. Acta Theriologica, Suppl. 4: 79-85.

Clarke G. M. and McKenzie J. A. 1992. Coadaptation, developmental stability and itness of insecticide resistance genotypes in the Australian sheep blowfly, Lucilia cuprina: A review. Acta Zoologica Fennica 191: 107-110.

Dobzhansky T. 1950. Genetics of natural populations. XIX. Origin of heterosis throug natural selection in populations of Drosophila pseudoobscura. Genetics 35: 288-302.

Ferguson M. M. 1986. Developmental stability of rainbow trout hybrids: genomic coadatation or heterozygosity? Evolution 40: 323-330.

Graham J. H. 1992. Genomic copadaptation and developmental stability in hybrid zones. Acta Zoologica Fennica 191: 121-131.

Gupta A. P. 1978. Developmental stability in species hybrids and backcross progenies of Drosophila. Evolution 32: 580-687.

Krasińska M. 1969. The postnatal development of F1 hybrids of European bison and dometic cattle. Acta Theriologica 14: 69-117.

Krasińska M. 1971a. Hybridization of European bison with domestic cattle. Part VI. Acta Theriologica 16: 413-432.

Krasińska M. 1971b. Postnatal development of B1 hybrids of European bison and domestic cattle. Acta Theriologica 16: 432-438.

Krasińska M. 1979. Postnatal development of European bison and domestic cattle lybrids of backcrosses B2 and B3. Acta Theriologica 24: 211-220.

Markow T. A. and Ricker J. P. 1991. Developmental stability in hybrids between the sibling species pair, Drosophila melanogaster and Drosophila simulans. Genetica 84: 115-121.

Olech W. 1987. Analysis of inbreeding in European bison. Acta Theriologica 32: 337-387.

Olech W. 1989. The participation of ancestral genes in the existing population of European bison. Acta Theriologica 34: 397-407.

Palmer R. A. and Strobeck C. 1986. Fluctuating asymmetry: measurement, analysis, patterrs. Annual review in Ecology and Systematic 17: 391-421.

Reeve E. C. R. 1960. Some genetic tests on asymmetry of sternopleural chaeta number in Lrosophila. Genetic Research 1: 151-172.

Sokal R. R. and Rohlf F. J. 1981. Biometry. Freeman, San-Francisco: 1-859.

Van Valen L. 1962. A study of fluctuating asymmetry. Evolution 16: 125-142.

Wallace B. 1953. On co-adaptation in Drosophila. American Naturalist 87: 343-358.

Zakharov V. M. 1981. Fluctuating asymmetry as an index of developmental homeostasis. Genetika (Beograd) 13: 241-256.

Zakharov V. M. 1987. [Animal asymmetry: population-phenogenetic approach.] Nauka Moskva: 1-216. [In Russian].

Zakharov V. M. 1992. Population phenogenetics: Analysis of developmental stability in natural populations. Acta Zoologica Fennica 191: 7-30.

Received 7 December 1995, revised 10 December 1996, accepted 8 March 1997. 